\title{
Perceived changes to quality of life indic ators following a physical activity intervention for recovering cancer patients: a qualitative study
}

\author{
Martyn Queen BEd (Combined Hons) MA PhD PGCert ${ }^{\mathrm{a}}$, Saul Bloxham BSc PhD ${ }^{\mathrm{b}}$, Phil Brown \\ BA MA PGCert ${ }^{\mathrm{c}}$, Melissa Coyle BSc MSc PGCert ${ }^{\mathrm{d}}$ and Ben Jane BSc MSc PGCert
}

a Doctor of Physical Activity and Health, University of St Mark \& St John, Plymouth, UK b Doctor of Exercise and Sport Science, University of St Mark \& St John, Plymouth, UK c Senior Lecturer in Sports Development, University of St Mark \& St John, Plymouth, UK d Lecturer in Sport \& Exercise Psychology, University of St Mark \& St John, Plymouth, UK e Senior Lecturer in Sport \& Health Science, University of St Mark \& St John, Plymouth, UK

\begin{abstract}
Aim: The aim of this study was to examine the perceived changes in quality of life (QoL) for a group of recovering cancer patients, following 6 months of physical activity.

Background: Evidence suggests that physical activity can improve the QoL of recovering cancer patients, reducing many of the side-effects of cancer and its related treatments, including depression, anxiety, chronic fatigue, with an improvement in physical and psychological health.

Method: A qualitative study with 14 mixed site cancer patients aged 43-70 (12 women, 2 men). The intervention was in 2 parts the first part was an 8-week physical activity programme, the second part related to a period of non-supervised, physical activity for 4 months (6 months in total). The programme took place at a University in the South West of England, UK. Semi-structured interviews with patients took place 3 times over 6 months. A grounded theory approach was used to analyse the data.

Results: We found that prior to the 6-month physical activity intervention many of the patients were anxious about being able to complete the initial 8 week programme. Anxieties related to low self-esteem and the chronic fatigue resulting from their cancer treatment. Consequently, several patients expressed concerns about their ability to help themselves self-manage their recovery through physical activity. On completion of the intervention the majority of patients described improvements in their perceived QoL in terms of their ability to self-manage and to engage in their self-efficacy, reporting increased energy levels and decreases in chronic fatigue.

Conclusion: Our study has provided valuable insights into how the perceived QoL of a group of recovering cancer patients can be improved through a combined 6-month period of supervised and independent physical activity. These findings serve as further evidence of the effectiveness of a person-centered healthcare approach for recovering cancer patients.
\end{abstract}

\section{Keywords:}

Cancer patients, chronic fatigue, distress, grounded theory, living with cancer, person-centered healthcare, physical activity, physical health, psychological health, qualitative, quality of life, recovery, self-efficacy

\section{Correspondence address}

Dr. Martyn Queen, University of St Mark \& St John, Faculty of Sport and Health Sciences, Plymouth, PL6 8BH, UK. E-mail: mqueen@marjon.ac.uk

Accepted for publication: 16 November 2015

\section{Introduction}

The number of people living with cancer in the UK is expected to rise from approximately 2.5 million to 4 million by 2030 [1]. A growing body of evidence exists showing that physical activity can reduce many of the effects of cancer-related treatments, including depression, anxiety, chronic fatigue and that it can improve physical and psychological health [2-6]. Research has also shown that breast cancer patients, who engage in physical activity programmes as part of their recovery can remain physically active for up to 5 years after completion of a programme, compared to those who did not [7]. Despite the known benefits of the impact that physical activity can have on cancer survivors, no clear physical activity guidelines exist for UK cancer patients. However, in countries such as Canada and the USA, where physical activity guidelines do exist, physical activity levels for recovering breast cancer patients have been reported to be as low as $37 \%$ in the USA and just $27 \%$ in Canada $[8,9]$. 
Furthermore, these figures for low physical activity takeup following cancer treatment may be even lower than reported, as the data obtained using self-report methods that have been shown to under-represent physical activity levels when compared to accelerometer data [10].

As more people are being successfully treated for cancer, there is a need to consider a more long-term approach to addressing patients' health-related Quality of Life (QoL) [11]. As cancer-related health problems can persist for many years following treatment, approaches to cancer survival should include the need to help patients self-manage their chronic conditions [12]. Selfmanagement of a chronic condition has been defined as a person's ability to manage the symptoms, treatment and the consequences of living with it [13]. However, such long term approaches challenge what has traditionally been a paternalistic paradigm whereby clinicians provide advice and prescribe medication and patients would largely do what they were told to do [11]. A randomised control trial (RCT) incorporating the use of Cognitive Behavioural Therapy techniques to promote routine physical activity and enhance QoL for prostate cancer patients found no improvements in QoL scores at 6-month and 12-month follow-up, nor any significant changes in physical activity measures [14]. However, caution should be applied when considering these findings as RCTs have been shown to underestimate physical activity in patients with chronic conditions, given that the experimental setting is not able to replicate practice [15]. In contrast, qualitative studies tend to represent physical activity interventions more favourably as they can capture patterns of patient behaviour, such as adherence, completion or changes in behaviour and mood throughout a programme [15].

Depressive symptoms and low mood state have been identified as some of the consequences faced by patients living with and beyond cancer. With specific reference to mental health, physical activity has been shown to have modest yet positive effects on depressive symptoms and significant improvements in mental health can be achieved when programmes are supervised and are at least 30 minutes in duration [2]. Group-based physical activity has also been shown to increase activity levels, general selfefficacy and produce subsequent reductions in fatigue and distress [16]. Similarly, improvements in self-efficacy have been associated with increased physical activity levels throughout a programme [17]. Levels of self-efficacy have also been shown to increase with repeated bouts of light to moderate intensity physical activity [18].

Research has identified a range of barriers for cancer patients wishing to participate in physical activity programmes, such as low self-efficacy and adverse treatment effects including chronic fatigue [19]. However, very few studies examined into how patients have overcome these barriers. The objectives of this qualitative study were to investigate the perceived changes in the patients QoL, post-physical activity intervention and then again at the 4 month follow-up. Given the low adherence and take-up rates of physical activity programmes that include structured formalised exercises [14], the intervention in this study included relevant lifestyle integrated physical activities.

\section{Method}

\section{Design}

We used a grounded theory approach [20] to analyse the perceived changes to the patients' QoL following their involvement with an 8-week physical activity programme and again at the 4-month follow-up. The data were collected using audio-recorded, semi-structured interviews between April and October 2014, at a University located in the South West of England, UK. The study comprised 3 data collection and analysis phases over 6-months. The research design adopted is noteworthy in that it contrasts with other studies in the exercise referral literature in 2 specific ways. Firstly, the majority of studies published in this area adopt a positivist approach [21-25], although some studies do adopt an interpretive approach [26-29]. Through using a qualitative approach to data collection and analysis, this study was able to investigate the patients' changing perceptions over a 6-month time period for the following QoL indicators of (i) self-efficacy, (ii) selfmanagement, (iii) chronic fatigue and (iv) increasing energy levels $[12,16,18]$. Secondly, the deployment of 3 data collection and analysis phases contrasts markedly with traditional data collection schedules in the literature, which tend to adhere to the life-cycle of the exercise referral scheme, that is, pre and post a 12-week intervention [15,26,30-33]. Some studies do include a 12-week followup $[34,35]$. However, these are not common. The approach we employ here therefore provides the opportunity to develop themes emerging from the first data collection phase, into lines of enquiry at a further point in time. This approach has provided some explanations for how the patients' perceived changes in their QoL during their recovery from cancer, as a consequence of becoming physically active over a 6-month period of time.

\section{Study setting}

The physical activity programme evaluated in this paper is the result of a partnership project between a University and a Macmillan Cancer Support Centre. The aim of the partnership was to improve the health and wellbeing of recovering cancer patients through referral into an 8-week physical activity programme. The programme was delivered by university teaching staff and supported by students. The objective of the programme was to promote independent physical activity through home-based strengthening exercise, posture awareness and walking activities. These were incorporated into activities of daily living to promote long-term sustainability and relevance to each individual patient.

Patients attended one, 2-hour session per week. The 2hour session was a combination of discussion to support patients to adopt a physically active lifestyle and activity, with the intention of increasing and sustaining physical activity. The programme utilised a range of behaviour change techniques, such as providing theoretical support for the use of physical activity, goal-setting, self- 
monitoring, social support, relapse prevention and barrier identification [36].

The practical elements of the programme were designed to introduce or re-acquaint patients with a range of activities such as walking, gym and home-based resistance exercise, swimming, badminton, flexibility, balance and posture exercises and cardiovascular exercises [37]. Following completion of the programme the patients were encouraged to continue to be physically active. Patients were referred to the programme by health professionals associated with the Macmillan Cancer Support Centre. The referral criteria into the programme included:

- $\quad$ to be deemed appropriate for participation by an oncology health professional

- $\quad$ to be a voluntary participant

- $\quad$ to have attended the Macmillan Cancer Support Centre

- $\quad$ to have attended an introductory talk about the physical activity programme

All of the patients undertook health screening assessments prior to the start of the programme that were re-assessed in the final week [37].

\section{Participants}

Having agreed to take part in the programme, 16 patients volunteered to participate in the research. The patients were selected on the basis of a convenience sample, as is congruent with grounded theory research $[20,38]$. Sixteen patients were provided with an information letter and consented to be interviewed at 3 designated points over the 6 -month data collection period ( 0,3 and 6 months). The first data collection period was prior to the take-up of the programme; the second period followed completion of the programme and the third period was at the 4-month followup. Fourteen patients were interviewed on all 3 occasions over the 6-month period. Two patients dropped out following the first set of interviews and did not attend the 8-week programme due to on-going health problems (46 interviews in total). Four of the 14 patients (negative cases) unable to sustain their physical activity up to the 4-month follow-up attended the final interview and were included in the analysis to provide an alternative perspective [20]. All 14 patients attended the 8 -week programme.

\section{Data collection methods}

All data were collected by the first 4 authors. Semistructured interviews were recorded on Olympus Digital Voice Recorders, transcribed verbatim and anonymised. The interviews took place at a university campus on all 3 occasions. To describe the study all patients were asked questions relating to their socio-demographic and morbidity characteristics at the start of the first interview, as shown in Table 1. The University of St Mark and St John Research Ethics Committee approved the study.
Table 1 Patients' socio-demographic, morbidity and pre-intervention diagnosis characteristics

\begin{tabular}{lcc}
\hline Characteristics & $\begin{array}{c}\text { Patients } \\
\text { Men }^{\mathrm{a}} \\
\mathrm{n}(\%)\end{array}$ & $\begin{array}{c}\text { Patients } \\
\text { Women }^{\mathrm{b}} \\
\mathrm{n}(\%)\end{array}$ \\
\hline Gender & $3(22)$ & $10(83)$ \\
Age in years [mean (SD)] & $68(2.1)$ & $54(8)$ \\
Ethnicity/Race & $3(100)$ & $10(100)$ \\
$\quad$ White & & \\
Cancer diagnosis & $0(100)$ & $8(80)$ \\
Breast & $3(100)$ & $0(100)$ \\
Prostate & $0(100)$ & $2(20)$ \\
Mouth & $0(100)$ & $1(10)$ \\
Kidney & $7(67)$ & $2(75)$ \\
Pre-intervention diagnosis period in years & $8(33)$ & $3(25)$ \\
\hline${ }^{a} n=3,{ }^{b} n=11$ & &
\end{tabular}

\section{Data analysis}

The memos that emerged from the coding processes were used as the method for generating grounded theory. We used the memos as a means of describing and explaining the patients' changing perceptions of QoL indicators over the 6-month data collection period. We manually analysed the data in order to understand fully the richness of the data through human interpretation [39]. To ensure a robust approach to the application of grounded theory, we ensured that a number of critical characteristics were implemented throughout the data analysis. These included consecutive data collection and analysis over a 6-month time period. This enabled the analysis to cyclically inform the data collection process as is recommended in grounded theory studies [40]. Sequential analysis facilitated the development of concepts and categories from the data while at the same time allowing new possibilities to emerge from the data via subsequent data collection episodes. Training on open and axial coding [20] was provided by the first author to the second, third and fourth authors, to enable data analysis to take place. The first author checked the analysis for consistency and reviewed the concepts and categories from the data in order to assure the continuation of theoretical development. Memos were used to formulate questions for subsequent sets of interviews. The first author advanced theoretical development through selective coding and the application of the axial coding paradigm, the second author assisted by reviewing this process [20]. Memos were used by the first 4 authors to explore the different dimensions of the emergent themes from the axial coded data, the first author reviewed this process for consistency. The final analytical characteristic used to ensure a robust approach to grounded theory analysis was the construction of the end product of the research [40]. This involved the first author selectively coding the data [20] and the developing of a 'core story' from the axial coded memos, from which a core category developed. This, in turn, led to the development of a conceptual model, as shown in Figure 1. This was followed by a descriptive account of the findings, supported by 
evidence from the lived experiences of the patients in the study.

To further ensure interpretive credibility, the first author applied the following aspects of trustworthiness to the data collection process. Credibility, through prolonged engagement with the data, triangulation, peer debriefing, negative case analysis and member checks. Transferability, through thick description and theoretical sampling. Dependability and Confirmability, through providing a clear audit trail and Reflection, through reflecting on the self and the method [41].

\section{Results}

Several of the patients reported that at the start of the physical activity programme their QoL was not as good as it had been before their cancer diagnosis. Prior to their take-up of the programme the majority of patients had expectations that it would improve their QoL and that they would become more energetic as a result of their engagement with it. Patient10 hoped that the programme would give her a little more energy to help her cope with everyday activities:

"I’m hoping it will give me that little boost of extra energy that I feel I need to help me with my day to day activities really.”

Patient 11 had an expectation that the programme would improve her QoL by increasing her confidence, along with the range of motion in her arm that had been restricted due to breast reconstruction surgery:

"Perhaps give me more confidence, starting the gym again. As I mentioned earlier, helping the movement in this arm again.”

Patient 8 also expected that the programme would improve her QoL and that it was the first step necessary for her to return to regular exercising:

"I think it will improve it because exercise is good for you. I always feel better after I've done exercise anyway, all the endorphins and the rest of it. I'd like to get back to doing more serious exercise so I can get that high that you get after you've been exercising."

In Figure 1 we have presented a conceptual model which is configured around the core category of 'QoL changes'. The concept of 'perceived QoL changes for recovering cancer patients' was the phenomena investigated and 'QoL changes' emerged as the core category. This category was selected as it best represented the views of the patients who perceived that becoming physically active had positively impacted on their QoL. The core category 'QoL changes' was central to all the other categories; it was identified in the data and explained variation as well as the main point made by the data, which are requirements of a core category [20]. Each aspect of the conceptual model is described below.
Figure 1 Conceptual model demonstrating patients' perceived changes to quality of life indicators following a physical activity intervention

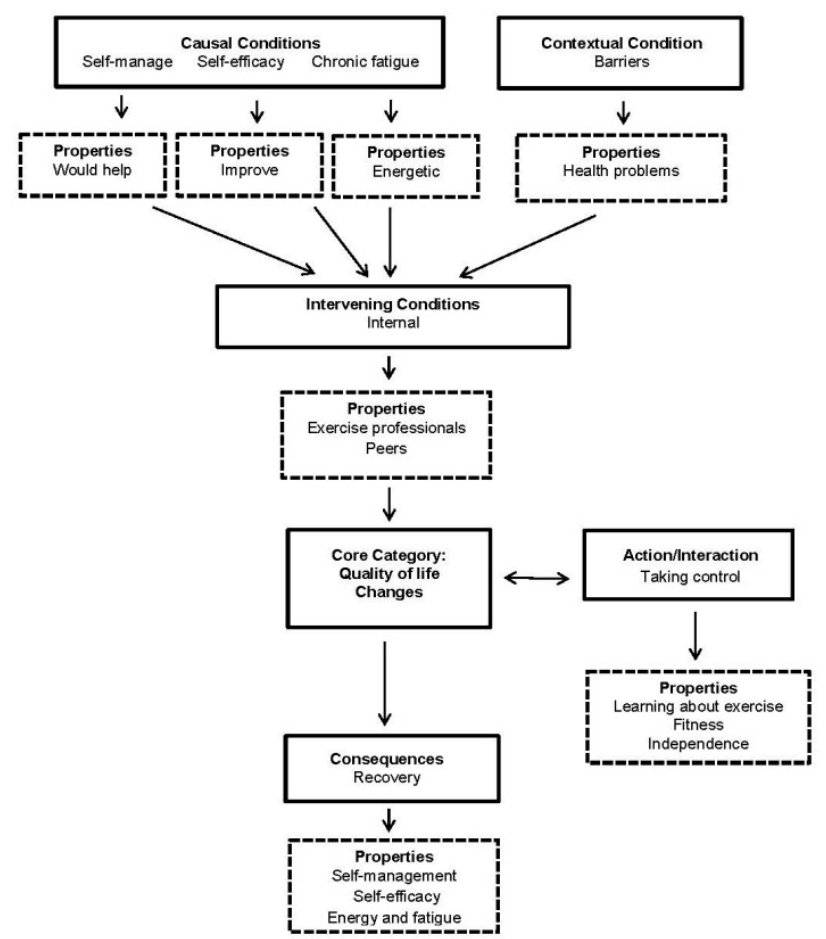

\section{Causal conditions - self-management, self- efficacy and chronic fatigue}

Three causal conditions emerged from the data. These were (i) self-management, (ii) self-efficacy and (iii) chronic fatigue. 'Causal conditions relate to sets of events or happenings that influenced the phenomena' [20]. The first causal condition 'self-management' considered the views held by the patients about whether their engagement with the programme would help them to self-manage their recovery from cancer. The property of the 'selfmanagement' causal condition considered the views held by the patients in relation to whether their engagement with physical activity 'would help' them to self-manage their recovery from cancer.

\section{Causal conditions - self-management}

Prior to the patients taking up the programme, they had different views as to whether the programme would help them to self-manage their recovery from cancer. Some patients believed that it would help, while others did not think so. One patient thought that if she became healthier she may be less reliant on the health professionals:

\section{"Maybe if I am healthier I won't need to attend any more appointments with health professionals.”}

Patient 8 was of the view that taking part in the programme would help her to continue self-managing: 
"I think I self-manage quite well, I think it will give me a little boost a little bit of extra support, a bit more of an incentive to carry on.”

Patient 4 thought that the programme would help her to continue to be physically active after she had completed it:

"I'm hoping it's going to have quite a big impact and that I carry on. I do enjoy swimming but hopefully there's going to be a few things that I would hopefully carry on."

In contrast to those patients who thought the programme would help them to self-manage their recovery, a minority were unsure if it would. Patient 13 did not feel that she was ready to self-manage yet, as she was still undergoing medical treatment:

"I really need that kind of support at the moment as I am not at full recovery. I need the doctors to keep an eye on me, of course there is need for medical support. Something could happen whilst I'm doing the exercises, so I have to check with the doctors that things are going well for me.”

Patient 5 stated that he did not believe the programme would have any impact on his ability to self-manage in his current situation, as his wife would be able to support him if necessary. However, he also believed that if this was not the case, the programme would help with his independence:

"It's a difficult one, me personally, it won't make any difference to me being independent. Because I'll never really be on my own to have to do it independently but if I was, it would be a marker to get up and do it.”

\section{Causal conditions - self-effic acy}

The second causal condition 'self-efficacy' related to how the patients perceived themselves prior to the start of the programme and whether their engagement with it would improve their self-efficacy. The property of the 'selfefficacy' causal condition considered the views held by the patients in relation to whether their engagement with physical activity would 'improve' their self-efficacy which had generally been low since their cancer diagnosis.

Prior to the start of the programme several of the patients perceived themselves to have low self-efficacy and several of them considered themselves to be depressed. Patient 1 explained how he felt weak as a result of his cancer treatment and how this had left him feeling frustrated:

\footnotetext{
“Yes, there's a lot I can’t do and I get frustrated because I can't do it. I just haven't got the strength. I've been told not to use the word 'can't', that's the negative side, I've got to look on the positive side."
}

For Patient 13, her lack of self-efficacy related to feeling weak and depressed as a result of her cancer diagnosis:
"Feeling weak, depressed, anxious and the thought of not trying to think I'll not do anything again in my life, and the thought that this is the end and that it's collapsing on top of me."

\section{Causal conditions - chronic fatigue}

The third causal condition 'chronic fatigue' related to how the patients identified experiencing chronic fatigue associated with their treatment and recovery and how this could negatively impact on their ability to engage with the programme. The property of 'chronic fatigue' casual condition considered the views of the patients that related to their expectations that they would become more 'energetic' through becoming physically active.

The majority of the patients stated that they had low energy levels and were concerned that this would make it difficult for them to engage with the physical activity programme. Patient 10 said that she did not feel that she had enough energy yet to exercise:

"In general terms I am still very well off I mean I can do most things... I just feel that, I haven't quite got that energy back that I need to exercise.”

Patient 7 was anxious about having enough energy to exercise:

"I feel slightly anxious yes, because my energy levels are much lower than I like and I get tired very quickly.”

Similar explanations were given by many of the patients in relation to concerns about their levels of fatigue and how this might impact on their ability to complete the programme. Patient 10 was also anxious about whether she would be able to do the exercises and cope on the programme:

"A bit of nervousness of about what I will be able to cope with I suppose, I'm hoping that there will be people there telling me when I'm doing it right and when I'm doing it wrong."

For Patient 8, her concerns related to the residual fatigue she was still experiencing following her treatment and how this made her feel tired the day after physical activity:

"I'm hoping it will help it. Improving my stamina because I do find that I fatigue quite easily still. For example, we had quite an active day yesterday and I feel today, not overly but I just feel weary today, I get residual fatigue. If I have a busy day one day, I feel it the following day and I would like to think it would improve my energy level."

Patient 14 hoped that engaging with the programme and becoming more physically active would give her more energy and motivation to start doing more, as the chronic fatigue associated with her treatment had prevented her from becoming active:

"I'm hoping it will make me more positive and give me a bit more get up and go, a bit more motivation. I think at the 
moment my lack of motivation is to do with the treatment but I'm hoping it will have a positive effect and give me the energy to go and do something."

\section{Contextual conditions - Barriers}

Contextual conditions are sets of conditions that intersect at a time and place creating a series of problems to which people respond through actions and interactions [20]. 'Barriers' was the theme that emerged from the contextual conditions category. The property of the 'barriers' theme related to additional 'health problems'. The perceived health problems were generally unrelated to the patient's cancer diagnosis and seen as a potential barrier to completing the programme and improving their QoL.

Just over half of the patients identified potential barriers that could have prevented them from starting the programme. Patient 2 thought that her knee problem could be a potential barrier to her success on the programme:

"Physically the knee, but I will throw myself into it as much as I can. But I think you know it's inevitable, because yes, it's there."

For patient 4, his back ache was his main concern:

"Obviously my back ache is my main concern really. I seem to go a month when it is OK and then it starts playing up again, that would be the only barrier."

Patient 6 was concerned that the programme would exacerbate her headaches:

"Will I have any energy to start something like this as I'm suffering really badly from headaches at the moment, they beat and bump and pulse, so I don't want to do anything that makes it worse.”

\section{Intervening condition - Internal}

Intervening conditions are conditions that alter the impact of the causal conditions on the phenomena [20]. The theme that emerged was 'internal' support systems. This theme related to the support systems while the patients were engaged with the programme, the properties of which included 'exercise professionals' and 'peers'.

The patients identified 2 key aspects of internal support during their time on the programme. This related to support from the exercise professionals and their peers on the programme. All of the patients identified how supportive the exercise professionals were. Patient 4 explained how they always listened to any questions she had:

"The team that ran the Programme were very good. If you had any questions, they would answer you and they showed a lot of interest in what we had to say, which was good and yeah gave advice.” were:

Patient 1 also emphasised how supportive the team
"It was the team. In all honestly I could not turn and say one did any more than the other, they were all brilliant. You could ask them for advice on anything and they would give it to you."

Patient 8 pointed out how even though there was a large group of patients they all received individual attention:

"Even though there was quite a big group of us doing it, they would make sure that they came round and spoke to us individually.”

The second aspect of internal support came from the patients' peers who were also participating in the programme. Patient 12 was able to give an example of how supportive the group had been to a patient, who had gone through breast reconstruction surgery half-way through the programme:

\footnotetext{
“One week we all had a moment's thought for one lady, because she was having her breast reconstruction. So I said how about it folks and we all shouted give it hell girl. She was in the next week and didn't have the scars or anything. I said I thought you had your operation last week. She replied yes and you have all been so supportive.”
}

A common theme evident from all of the patients was how the group-based intervention enabled them to discuss their cancers informally and at their own pace with the other patients on the programme. Patient 14 felt that the discussions she had with her peers on the programme were informative and reassuring:

\footnotetext{
"It was nice to have other people there who have gone through the same things, because you could talk to them and they would say yes I've suffered that or I had that and it got better. People understood because they were or had gone through it."
}

Patient 9 also identified how beneficial it was to be able to discuss her cancer with others who were currently, or had been, in the same position as her:

"The group of people were all friendly and we were able to talk about our experiences, which you can't do at home. There's not quite the understanding from people who have not walked down the same path.”

\section{Actions and interactions - taking control}

Actions and interactions are purposeful acts undertaken to solve a problem and in doing so shape the phenomena [20]. The theme identified in the data was 'taking control'. The properties of the 'taking control' theme related to 'learning about exercise', 'fitness' and 'independence'.

Most of the patients felt that taking part in the programme had enabled them to regain control of their lives. During their period of cancer treatment and prior to their take-up of the programme the patients believed that their lives had not been their own, due to being under the control of the medical establishment. The patients identified that through becoming physically active they 
were able to start taking control of their recovery from cancer and that made them feel that they were actively regaining control of their lives. Patient 4 explained how she had learnt about physical activity:

"I’ve learnt that I can swim better using my arms and my legs. There are a few tips that I've picked up along the way. The exercises that we were given and the bit of homework we were given each week, it's been helpful.”

Patient 3 said that she had learnt about core muscles and how to exercise them:

"I learnt about working core muscles and how important they are for maintaining muscle strength.”

Patient 10 had learnt that physical activity could be fun and that when it was, it was possible to be physically active without realising that you were actually doing it:

\begin{abstract}
"The programme pointed the way to keeping fit while having fun such as badminton and table tennis. We even went out and played a tag game in the field, as well as orienteering and stuff like that. These were all ways of keeping fit without realising you're doing it.”
\end{abstract}

Some of the other patients identified that as they had become fitter, they were able to do more, which in turn made them feel like they were taking control of their recovery. Patient 2 explained that as she had become more active, she realised that she did not want to go back to a stagnant way of life:

"I'm doing more and I'm feeling good about doing more. That is my aim to keep going on. I don't want to stagnate again, like I did before.”

Patient 10 said that since the programme she had been doing more, which was making her feel better:

"On the whole, there is definitely a link between me doing more and me feeling better within myself. It spurs me along as well."

Patient14 explained how she had purchased some exercise equipment to enable her to become physically active independently of the programme:

"I bought one of those balls you can sit on in front of the $\mathrm{TV}$, the bands, hoola-hoop and skipping rope. So I'm going to make time and they said even if it's only 5 minutes now and 5 minutes later on, that's 10 minutes you would have done.”

Patient 12 explained how he was developing his physical activity independently of the programme by exercising in his garage at a pace that he could manage:

"Now I am able to put a mat down in my garage at home, and go through those exercises, little by little at a speed that I can manage.”

\section{Consequences - Rec overy}

The consequences category related to the outcomes resulting from the actions and interactions identified above [20]. The consequence theme identified in the data was 'recovery'. This theme related to the perceived impact that 6-months of physical had on the patients QoL. The 'recovery' theme had three properties, which were 'selfmanagement', 'self-efficacy', 'energy and fatigue'. These outcomes were generally attributed to the time the patients had spent on the programme and the resultant physical activity behaviour. However, not all of the patients experienced these improvements in QoL; their views (negative cases) are also presented as a means of providing an alternative perspective.

Following completion of the programme most of the patients perceived that the programme had helped them to self-manage their recovery. Various perspectives were given by the patients on how the programme had helped them to do this. Patient 1 identified that the programme had not made any difference to his cancer treatment, which was still on-going. However, he said that since completing the programme, his depression had reduced to such an extent that he had reduced his medication to one tablet every other day:

"Before I started the programme I was in a deep depression, I was really down and took anti-depressants, but now I only take them every other day. The cancer side, it hasn't made any difference to that, at the moment I'm still getting the hormone injections, they're every 3 months. The programme helped me psychologically a great deal.”

Patient 2 stated that she had also experienced a reduction in medication that she had been prescribed for her diabetes. She thought that this could be the result of her engagement with the programme and resultant improvements in her physical activity:

“The pharmacist's check said instead of 850mg 3 times a day I am taking $500 \mathrm{mg}$ twice a day so that's reduced by half. That could be a direct result of the programme.”

Patient 13 identified that having completed the programme she now felt able to self-manage to a greater extent as she was now less reliant on her family for support:

"In lots of ways, the programme has helped me to selfmanage because I was depending too much on my daughter and my husband. Now I can do most things for myself without too much stress.”

Patient 14 explained how the programme had helped her to self-manage. This related to how being in a group with other recovering cancer patients had helped her to come to terms with her cancer:

"I think it helped being with other people that had the same experience. You feel less like what has happened to you is unusual when you see another person getting better." 
The majority of the patients continued to report increases of self-efficacy at the 6-month data collection point. Patient 1 stated that his self-confidence had continued to improve. He also believed that being active and going out walking prevented him from returning to his previously depressive state of mind:

"I think my self-confidence has been alright, it’s improved. I'm a lot more confident to go out and walk and to do other things rather than sat vegetating and getting all depressed.”

Patient 3 also explained that she continued to feel confident about her physical ability and how this had positively impacted on her depressive moods:

"In terms of my physical ability I am still confident. My negative mood will always be there but it is reducing slowly... I think that during that programme the mind is taken away from that moment of being sad. In the group we could talk things over and that takes your mood away.”

For Patient 2 her improved self-confidence related to how she could now manage relatively simple activity that her cancer had prevented her from doing:

"My self-confidence is better. I feel better because I am more active. I can go up and down the stairs now without difficulty. The cancer took a lot away initially but so much has been given back to me.”

Following 6-months of physical activity most of the patients identified increased energy levels and decreased levels of fatigue. The patients attributed this to their time on the programme and their resultant increases in physical activity over the 6-month period of time. Patient 1 explained how his energy and fitness levels had improved:

"Yes I have a lot more energy to do things. I walk down to the supermarket a couple of times a week, there and back.”

One patient explained how her increased energy also enabled her to go shopping and do the housework, which she had been unable to do before she had embarked on the programme:

"Well definitely because I couldn't walk up to the shops you know, I would have to stop half the time. Now I do my shopping and come back. I can also go through my house now cleaning and doing housework, whereas I couldn't. So I've definitely got better energy levels."

At the end of the programme many of the patients identified how their levels of tiredness had reduced, compared to when they had started. Patient 1 put this down to an increase in stamina:

“I don’t get so tired, I’ve got more stamina and I don’t get tired quite so quickly."

Patient 8 identified that on the day following her physical activity, she did not get as tired as she used to:
"I don't think I'm getting as tired as I used to. It used to be that if I had a day of doing physical exercise, the following day I would feel tired. Sometimes that does happen, but not as often.”

Patient 4 also noticed how she was less tired than she was at the beginning of the programme, and that her increase in energy enabled her to do more:

"I suppose I'm less tired because I can go on and on but the minute I sit down I do come to a grinding halt. So obviously I have become more active without noticing it.”

However, not all of the patients reported improvements in the key areas of QoL, self-efficacy, energy and fatigue. Patient 3 identified that her selfconfidence had decreased. However, she put this down to a lack of support after completing the programme:

"I'd say if anything it's decreased, but that's probably because I'm trying to do it on my own, if I'm honest."

Patient 14 identified that her QoL improved while she was on the programme, but the pressure of having to return to work made her feel that it had deteriorated:

"Since completing the programme I was quite optimistic but since going back to work full-time, I've been disappointed in myself... At the moment I am finding it a struggle just to keep up with the day to day life... I'm concentrating on making sure that I get to work and do a full day's work, that I don't ring in sick.”

Patient 7 explained that her energy levels had dropped following a bout of illness toward the end of the programme, which had made it difficult for her to continue with her physical activity:

"I was doing a keep fit thing before I got ill, getting ill has stopped me, because I haven't had the energy levels. I couldn't sustain an hours keep fit at the moment, so I've kind of dropped out of that, but I will drop in again as soon as I feel up to it.”

Other examples of improved QoL included improvements in mood swings, gaining a more positive outlook on life, being able to plan activities to start leading a normal life. For Patient 3, her improved QoL related to her improved moods that she attributed to her sustained physical activity over the 6-month data collection period:

"It's got better definitely. Everything that I've been doing has helped and my moods have definitely improved. I think it's just the fact that you want to have the best QoL you can while you can.”

For Patient 10, improved QoL related to the positive outlook she had gained as a result of her improved physical and mental health, which she attributed to physical activity:

"I have a more positive outlook on life. The improvements I've seen in my health have improved me mentally as well as physically. Obviously, going back to work was a big 
thing for me, but I now have that every day back to normal feeling."

Patient 13 explained that being physically active had enabled her to start leading a normal life, as she now felt able to start planning for the future:

\begin{abstract}
"I would say it has a positive impact on my QoL because when you are sick you can't really do anything, you can't plan much. But when you are active you can plan and see what can be done besides your illness to lead a normal life, so it has helped quite a lot.”
\end{abstract}

\section{Disc ussion}

While physical activity has a role in improving selfreported QoL for recovering cancer patients, the structure and design of a programme can also be of relevance [42]. A study compared a group intervention to an individual approach to physical activity [43]. They found that while QoL improved in both groups of breast cancer survivors, only those in the individual intervention experienced a significant improvement compared to usual care [43]. The findings from our study are in contrast to that of others [43], in that ours was a group-based intervention and the majority of patients reported improvements in their QoL. However, differences in study design and approach preclude detailed comparisons.

Prior to taking up the programme the patients in our study had mixed views of how their engagement would help them to self-manage their recovery. A systematic review of self-management interventions for prostate cancer patients has also shown as with our study, that physical activity interventions can be a viable way of providing healthcare solutions to improve psychological problems associated with cancer diagnosis [44]. Having completed the programme, several patients in our study identified that while it had not directly impacted on their cancer, it had helped them to self-manage some of the psychological aspects associated with their diagnosis. Two patients believed that their reduction in antidepressant and type 2 diabetes medication was attributed to time spent on the programme and their subsequent physical activity. A different patient identified how the programme had impacted on her life- role, to the extent that she had become more physically active and less dependent on her family for support. Several patients explained that the support from the other patients on the programme enabled them to come to terms with the psychological consequences of their cancer.

Improvements in self-efficacy have been associated with increased physical activity [17], at light to moderate intensity [18], supervised and not conducted at home [2]. The findings from our study are in agreement with others $[2,17,18]$ as self-efficacy improved with 8 -weeks of light to moderate physical activity. However, our findings also contrast to that of others $[17,18]$, as the main explanation given for improved self-efficacy in our study related to the patients knowing that non-supervised or structured physical activity was possible for them. Consequently, this had given the patients hope for a healthier future lifestyle. In contrast to a study that found self-efficacy improved when physical activity was not undertaken at home [2], our study supports the use of home-based activity, as it included a 4-month period of self-managed unsupervised physical activity conducted independently of the programme. Explanations for sustained physical activity included the use of pedometers as a motivational tool and have been reported in research elsewhere [37].

Chronic fatigue has been reported as a significant barrier to physical activity participation for breast cancer survivors [45]. Prior to the take-up of the programme in our study half of the patients reported reduced mobility and chronic fatigue following surgery, chemotherapy, or radiotherapy, as barriers that might prevent them from participating. Reductions in fatigue have been associated with increases in physical activity for recovering cancer patients [16]. Our study also found that most of the patients reported decreases in fatigue and increased energy levels following the 6-month physical activity intervention.

While research has identified chronic fatigue as a barrier for cancer patients participating in physical activity programmes [45], very few studies have examined how patients can overcome this. Our study has shown that patients' fatigue related pre-exercise anxiety can be reduced when they observed other cancer patients exercising in a closely supervised environment. Therefore, our study has identified that exposure to exercising cancer patients prior to entry into a physical activity care pathway, could reduce the barriers that have been identified with patient take-up of physical activity interventions. Observing other cancer patients exercising showed these patients that physical activity was possible for them.

In summary, this study has produced further evidence that physical activity can help improve the QoL for recovering cancer patients. Strengths include the transferability of the findings to similar settings and the robust approach to data analysis that is commensurate with grounded theory methodology and qualitative research more generally [20,40,46]. However, our study has limitations and these should be fully considered. They include the fact that the patients selected for the study were based on a convenience sample, drawn by the Macmillan Cancer Support Centre. This may have resulted in only those patients who were more likely to adhere to the programme being included in the study, which may have given a limited perspective. Nevertheless, the sample size $(n=14)$ and the common referral protocol of exercise referral schemes generally, ensure that many of the findings are transferable to similar exercise programmes based in the community, accessed through a health professional referral.

\section{Conclusions}

This evaluation, by implementing a qualitative approach, has provided evidence that our physical activity intervention improved QoL for recovering cancer patients who adhered to it. QoL indicators included self-assessed 
improvements in self-managing their recovery, improvements in self-efficacy, increased energy and reductions in chronic fatigue. The patients attributed their improvements in QoL indicators to the time spent on the programme and their continued activity leading to the 4month follow-up. Consequently, the patients believed that the intervention had enabled them to start taking control of their recovery from cancer and to continue to live their lives.

The findings from our study confirm the value and benefits of a physical activity intervention for cancer survivors. As such, this evaluation adds to the current literature on the impact of physical activity for improving the QoL of recovering cancer patients. However, more research is necessary to assess the impact of such interventions in order to understand more about the role of such an intervention for health improvement. For example, the evidence base would benefit from longitudinal observational research with sufficient follow-up to determine whether improvement is sustained in the long term (12-months) and very long term (5-years); the impact of the intervention on family members and the cost effectiveness of such interventions with regard to sustainability of the service.

\section{Acknowledgements and Conflicts of Interest}

We thank the patients, the referring health professionals, the exercise professionals and students who ran the programme. We would also like to thank the Macmillan Cancer Support Centre staff for their help and commitment, without which the study would not have been possible. We declare no conflicts of interest with respect to the authorship and/or publication of this article. No funding was received for this research.

\section{References}

[1] Maddams, J., Utley, M. \& Møller, H. (2012). Projections of cancer prevalence in the United Kingdom, 2010-2040. British Journal of Cancer 107 (7) 1195-1202.

[2] Craft, L.L., Vaniterson, E.H., Helenowski, I.B., Rademaker, A.W. \& Courneya, K.S. (2012). Exercise effects on depressive symptoms in cancer survivors: a systematic review and meta-analysis. Cancer Epidemiology Biomarkers \& Prevention 21, 3-19.

[3] McNeely, M.L., Campbell, K.L., Rowe, B.H., Klassen, T.P., Mackey, J.R. \& Courneya, K.S. (2006). Effects of exercise on breast cancer patients and survivors: a systematic review and meta-analysis. Canadian Medical Association Journal 175 (1) 34-41.

[4] Sabiston, C.M. \& Brunet, J. (2011). Reviewing the benefits of physical activity during cancer survivorship. American Journal of Lifestyle Behaviour 6, 167-177.

[5] Carmichael, A.R., Daley, A.J., Rea, D.W. \& Bowden, S.J. (2010). Physical activity and breast cancer outcome: A brief review of evidence, current practice and future direction. European Journal of Surgical Oncology 36 (12) 1139-1148.

[6] Harriss, D.J., Cable, N.T., George, K., Reilly, T., Renehan, A.G. \& Haboubi, N. (2007). Physical activity before and after diagnosis of colorectal cancer: disease risk, clinical outcomes, response pathways and biomarkers. Sports Medicine 37 (11) 947-960.

[7] Mutrie, N., Campbell, A., Barry, S., Hefferon, K., McConnachie, A., Ritchie, D. \& Tovey, S. (2012). Fiveyear follow-up of participants in a randomised controlled trial showing benefits from exercise for breast cancer survivors during adjuvant treatment. Are there lasting effects? Journal of Cancer Survivorship 6 (4) 420-430.

[8] Blanchard, C.M., Courneya, K.S. \& Stein, K. (2008). Cancer survivors' adherence to lifestyle behaviour recommendations and associations with health-related QoL: results from the American Cancer Society's SCS-II. Journal of Clinical Oncology 26, 2198-2204.

[9] Courneya, K.S., Katzmarzyk, P.T. \& Bacon, E. (2008). Physical activity and obesity in Canadian cancer survivors: population-based estimates from the 2005 Canadian Community Health Survey. Cancer 112, 2475-2482.

[10] Prince, S.A., Adamo, K.B., Hamel, M.E., Hardt, J., Gorber, S.C. \& Tremblay, M. (2008). A comparison of direct versus self-report measures for assessing physical activity in adults: a systematic review. International Journal of Behavioural Nutrition and Physical Activity 5, 56-56.

[11] McCorkle, R., Ercolano, E., Lazenby, M., Schulman-Green, D., Schilling, L.S., Lorig, K. \& Wagner, E.H. (2011). Self-management: Enabling and empowering patients living with cancer as a chronic illness. CA: A Cancer Journal for Clinicians 61 (1) 50-62.

[12] Rao, A.V. \& Demark-Wahnefried, W. (2006). The older cancer survivor. Critical Reviews in Oncology/Hematology 60 (2) 131-143.

[13] Barlow, J., Wright, C., Sheasby, J., Turner, A. \& Hainsworth, J. (2002). Self-management approaches for people with chronic conditions: a review. Patient Education and Counseling 48 (2) 177-187.

[14] Carmack Taylor., C.L., Demoor, C., Smith, M.A., Dunn, A.L., Basen-Engquist, K., Nielsen, I., Pettaway, C., Sellin, R., Massey P. \& Gritz, E.R. (2006). Active for Life After Cancer: A randomized trial examining a lifestyle physical activity program for prostate cancer patients. Psycho-Oncology 15 (10) 847-862.

[15] Gidlow, C., Johnston, L.H., Crone, D. \& James, D.V.B. (2008). State of the Art Reviews: Methods of Evaluation: Issues and Implications for Physical Activity Referral Schemes. American Journal of Lifestyle Medicine 2 (1) 46-50.

[16] Buffart, L.M., Ros, W.J.G., Chinapaw, M.J.M., Brug, J., Knol, D.L., Korstjens, I. \& May, A.M. (2014). Mediators of physical exercise for improvement in cancer survivors' quality of life. Psycho-Oncology 23 (3) 330-338. [17] Pinto, B.M., Frierson, G.M., Rabin, C., Trunzo, J.J. \& Marcus, B.H. (2005). Home-Based Physical Activity Intervention for Breast Cancer Patients. Journal of Clinical Oncology. 23 (15) 3577-3587. 
[18] Blacklock, R., Rhodes, R., Blanchard, C. \& Gaul, C. (2010). Effects of exercise intensity and self-efficacy on state anxiety with breast cancer survivors. Oncology Nursing Forum 37 (2) 206-212.

[19] Robertson, L., Richards, R., Egan, R. \& Szymlek-Gay, E.A. (2013). Promotion and support of physical activity among cancer survivors: a service provider perspective. Psycho-Oncology 22 (2) 441-446.

[20] Strauss, A.L. \& Corbin, J. (1998). Basics of Qualitative Research. Techniques and Procedures for Developing Grounded Theory (2nd edn.). California: Sage. [21] Crone, D. \& Guy, H. (2008). "I know it is only exercise, but to me it is something that keeps me going”: A qualitative approach to understanding mental health service users' experiences of sports therapy: Feature Article. International Journal of Mental Health Nursing 17 (3) 197-207.

[22] Harrison, R.A., Roberts, C. \& Elton, P.J. (2005). Does primary care referral to an exercise programme increase physical activity 1 year later? A randomized controlled trial. Journal of Public Health 27 (1) 25-32.

[23] Hillsdon, M., Thorogood, M., White, I. \& Foster, C. (2002). Advising people to take more exercise is ineffective: a randomized controlled trial of physical activity promotion in primary care. International Journal of Epidemiology 31 (4) 808-815.

[24] James, D., Mills, H., Crone, D., Johnston, L.H., Morris, C. \& Gidlow, C.J. (2009). Factors associated with physical activity referral completion and health outcomes. Journal of Sports Sciences 27, 1007-1017.

[25] Morgan, O. (2005). Approaches to increase physical activity: Reviewing the evidence for exercise-referral schemes. Public Health 119 (5) 361-370.

[26] Crone, D., Johnston, L. \& Grant, T. (2004). Maintaining quality in exercise referral schemes: A case study of professional practice. Primary Health Care Research and Development 5, 96-103.

[27] Sharma, H., Bulley, C. \& van Wijck, F. (2012). Experiences of an exercise referral scheme from the perspective of people with chronic stroke: a qualitative study. Physiotherapy 98, 336-343.

[28] Vinson, D. \& Parker, A. (2012). Exercise, service and support: client experiences of physical activity referral schemes (PARS). Qualitative Research in Sport, Exercise and Health 4 (1) 15-31.

[29] Wormald, H., Waters, H., Sleap, M. \& Ingle, L. (2006). Participants' perceptions of a lifestyle approach to promoting physical activity: targeting deprived communities in Kingston-upon-Hull. BMC Public Health 6, 202-212.

[30] Dinan, S., Lenihan, P., Tenn, T. \& Iliffe, S. (2006). Is the promotion of physical activity in vulnerable older people feasible and effective in general practice? British Journal of General Practice 56 (531) 791-793.

[31] Dugdill, L., Graham, R.C. \& McNair, F. (2005). Exercise referral: the public health panacea for physical activity promotion? A critical perspective of exercise referral schemes; their development and evaluation Ergonomics 48 (11-14) 1390-1410.

[32] James, D.V.B., Johnston, L.H., Crone, D., Sidford, A.H., Gidlow, C., Morris, C. \& Foster, C. (2008). Factors associated with physical activity referral uptake and participation. Journal of Sports Sciences 26 (2) 217-224. [33] Leijon, M.E., Bendtsen, P., Ståhle, A., Ekberg, K., Festin, K. \& Nilsen, P. (2010). Factors associated with patients self-reported adherence to prescribed physical activity in routine primary health care. BMC Family Practice 11 (38) 1-9.

[34] Damush, T.M., Stump, T.E., Saporito, A. \& Clark, D.O. (2001). Predictors of Older Primary Care Patients' Participation in a Sub maximal Exercise Test and a Supervised, Low-Impact Exercise Class. Preventative Medicine 33, 485-494.

[35] James, D.V.B., Crone, D., Curry, N. \& Gidlow, C. (2010). Report on the evaluation of the South Staffordshire Physical Activity Care Pathway. University of Gloucestershire, U.K.

[36] Michie, S. \& Johnston, M. (2012). Theories and techniques of behaviour change: Developing a cumulative science of behaviour change. Health Psychology Review 6 (1) 1-6.

[37] Queen, M., Crone, D. \& Parker, A. (2015). Long-term Engagement With a Practice-based Exercise Referral Scheme: Patients' Perceptions of Effectiveness. European Journal for Person Centered Healthcare 3, 369-376.

[38] Bryman, A. (2012). Social Research Methods (4th edn.). Oxford: Oxford University Press.

[39] Kelle, U. (2005). Emergence vs. 'Forcing' of Empirical Data? A Crucial Problem of 'Grounded Theory' Reconsidered. Forum: Qualitative Social Research 6 (2) 27.

[40] Hutchinson, A.J., Johnston, L. \& Breckon, J. (2011). Grounded Theory Based Research with Exercise Psychology: A Critical Review. Qualitative Research in Psychology 8, 247-272.

[41] Lincoln, Y.S. \& Guba, E.G. (1985). Naturalistic Enquiry. California: Sage.

[42] Vallance, J.K., Culos-Reed, S.N., Mackenzie, M. \& Courneya, K.S. (2012). Physical Activity and Psychosocial Health among Cancer Survivors. In: Routledge Handbook of Physical Activity and Mental Health. Ekkekakis, P., (ed.) pp. 518-529. Abingdon, Oxon: Routledge.

[43] Naumann, F., Munro, A., Martin, E., Magrani, P., Buchan, J., Smith, C. \& Philpott, M. (2012). An individual-based versus group-based exercise and counselling intervention for improving quality of life in breast cancer survivors. A feasibility and efficacy study. Psycho-Oncology 21 (10) 1136-1139.

[44] Cockle-Hearne, J. \& Faithfull, S. (2010). Self-management for men surviving prostate cancer: a review of behavioural and psychosocial interventions to understand what strategies can work, for whom and in what circumstances. Psycho-Oncology 19 (9) 909-922.

[45] Shapiro, C.L. \& Recht, A. (2001). Side effects of adjuvant treatment of breast cancer. New England Journal of Medicine 344 (26) 1997-2008.

[46] Hammersley, M. (1992). What's Wrong with Ethnography. Oxon: Routledge. 